Materials

\section{Spontaneous formation of inorganic helices}

\section{ttempts to generate films, wires,} helices, rings and regular patterns out of inorganic materials ${ }^{1-10}$ have been going on for the past 100 years. We show here that stable helices of porous manganese oxide materials can be formed spontaneously from uniform sols and that they are excellent semiconductors. These inorganic helices contain micropores, can be converted into other structures, and their composition can be varied.

Tetramethyl ammonium $\left(\mathrm{TMA}^{+}\right)$permanganate salts in 2-butanol/ $\mathrm{H}_{2} \mathrm{O}$ form sols that when heated in open capillary tubes can form ring and helical gels (Table 1 and Fig. 1). Helices are produced from concentrated sols and separated rings at low concentrations $\left(10^{-3}\right)$. The spacing between rings increases from the top to the bottom end of the capillary, as in the spacing law demonstrated by Liesegang rings ${ }^{11}$.

When helices form, the number of turns per unit length is primarily related to the starting concentration of the sol, whereas their diameters are mainly influenced by the capillary diameter and range from millimetres to less than $30 \mu \mathrm{m}$, with lengths of up to $25 \mathrm{~cm}$. Free-standing helices can be obtained by cutting the tubes, or by using water to detach them from the capillary wall.

The formation of helices starts first by virtue of a contraction of the sol-gel as a result of solvent evaporation. The elastic gel then buckles into a helical shape, possibly because of the capillary pressure applied at its upper end by the surrounding fluid. Further evaporation of solvent eliminates this capillary pressure and the gel expands from the bottom to the top of the capillary (see http://www.lib.uconn.edu/chemistry/ SuibGroup/suibg.html). We are investigating the mechanism of this process by quantifying the contribution and interplay of gel anisotropy and elasticity, wetting and dewetting, capillarity, and agglomeration of the sol particles that combine to produce these remarkable shapes.

Ion exchange of the TMA helix with $\mathrm{K}^{+}$leads to crystalline helices with composition $\mathrm{K}_{0.93}^{+} \mathrm{Mn}_{2.1}^{4+} \mathrm{Mn}_{1.9}^{3+} \mathrm{O}_{7}(\mathrm{OH})_{1.03} \cdot 2.7 \mathrm{H}_{2} \mathrm{O}$; the lattice parameters are similar to those of synthetic birnessite (OL-1; ref. 12). Ion exchange is rapid, indicating that these materials are highly permeable. Thermal treatment of the helices of K-OL-1 at $500{ }^{\circ} \mathrm{C}$ leads to the formation of an octahedral molecular-sieve (OMS) tunnel structure of synthetic cryptomelane (OMS-2), and a composition of $\mathrm{K}_{1.86}^{+} \mathrm{Mn}_{4.7}^{4+} \mathrm{Mn}_{3.3}^{3+} \mathrm{O}_{14.57}$ $(\mathrm{OH})_{1.43} \cdot 0.7 \mathrm{H}_{2} \mathrm{O}$ with an average oxidation state for manganese of 3.58 .

We examined the K-OMS-2 helices by scanning and transmission electron microscopy. Striations are evident along the length, indicative of a fibrous structure, corroborated by the direction of crack propagation from sample preparation. The helix cores are usually solid, however, with secondary spiralling along the radial direction of the helix being sometimes seen. The helix cores are usually solid.

The microstructure leads to microporosity of the $2 \times 2$ crystal structure of OMS-2, mesoporosity in between the colloidal crystallites, and a net alignment and connectivity of the microporous network along the length of the helix. This alignment leads to conduction along the helix and, as a result of the porosity, rate processes such as ion exchange are enhanced owing to fast dif-

\begin{tabular}{|c|c|c|c|c|}
\hline Sample & $I D(m m)$ & Time (h) & {$[\mathrm{Mn}](\mathrm{M})$} & Observations \\
\hline A & 3.0 & 140 & $1.0 \times 10^{-1}$ & Formation inside the glass tube \\
\hline $\mathrm{B}$ & 3.0 & 140 & $1.0 \times 10^{-1}$ & Formation on the external surface of the glass tube \\
\hline C & 1.2 & 24 & $1.0 \times 10^{-1}$ & Formation inside the glass tube \\
\hline $\mathrm{D}$ & 1.2 & 24 & $9.0 \times 10^{-2}$ & Formation inside the glass tube \\
\hline E & 1.2 & 24 & $8.0 \times 10^{-2}$ & Formation inside the glass tube \\
\hline $\mathrm{F}$ & 1.2 & 24 & $7.0 \times 10^{-2}$ & Formation inside the glass tube \\
\hline G & 1.2 & 24 & $5.0 \times 10^{-2}$ & Formation inside the glass tube \\
\hline 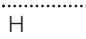 & 1.2 & 48 & $5.0 \times 10^{-2}$ & Formation inside the glass tube \\
\hline 1 & 1.2 & 24 & $5.0 \times 10^{-2}$ & Helix post-heated at $500^{\circ} \mathrm{C}$ for $2 \mathrm{~h}$ \\
\hline J. & 0.8 & 24 & $1.0 \times 10^{-1}$ & Helix formed in a quartz tube \\
\hline $\mathrm{k}$ & 0.5 & 24 & $1.0 \times 10^{-1}$ & Helix formed in a glass tube \\
\hline L & 0.2 & 24 & $1.0 \times 10^{-1}$ & Helix formed in a GC capillary tube \\
\hline $\mathrm{M}$ & 1.2 & 24 & $5.0 \times 10^{-3}$ & Ring formation \\
\hline N & 1.2 & 24 & $1.0 \times 10^{-3}$ & Mixture of rings and helices formed \\
\hline $\mathrm{O}$ & 1.2 & 24 & $1.0 \times 10^{-3}$ & Only micro-rings formed \\
\hline
\end{tabular}

ID, internal diameter of capillary tube; [Mn], manganese concentration (molar). A colloidal solution of lamellar manganese oxide (0.1M in Mn) was prepared by stirring $10 \mathrm{~mol}\left[\mathrm{~N}_{(}\left(\mathrm{CH}_{3}\right)_{4}\right] \mathrm{MnO}_{4}$ in $100 \mathrm{ml}$ of distilled deionized water and $30 \mathrm{ml}$ of 2-butanol at room temperature. After $30 \mathrm{~min}$, a dark-red-brown solution formed in the lower aqueous layer was separated off and used undiluted or diluted (down to $0.001 \mathrm{M} \mathrm{in} \mathrm{Mn).} \mathrm{Solutions} \mathrm{were} \mathrm{put} \mathrm{into} \mathrm{open-ended} \mathrm{capillaries.}$ Angles of tubes between $45^{\circ}$ and $90^{\circ}$ give well-formed helices. Solvent evaporation in an oven at $85^{\circ} \mathrm{C}$ produced helices as the sol shrank to form a gel $(<12 \mathrm{~h})$. A gel of $\left[\mathrm{N}\left(\mathrm{CH}_{3}\right)_{4}\right]_{0.93}^{+} \mathrm{Mn}_{2.1}^{4+} \mathrm{Mn}_{1.9}^{3+} \mathrm{O}_{7}(\mathrm{OH})_{1.03} \cdot 5 \mathrm{H}_{2} \mathrm{O}$, with a manganese average oxidation state of 3.52 , was formed after heating at $85^{\circ} \mathrm{C}$ for $160 \mathrm{~h}$ in capillary tubes of ID $3 \mathrm{~mm}$. Theoretical composition (experimental via inductively coupled plasma and combustion analyses in parentheses): for $\mathrm{TMA}_{y} \mathrm{MnO}_{x}$ helix, \%C 8.82 (10.58), \%H 4.36 (4.47), \%N 2.57 (2.86); for K-OL-1 helix, \%C 0 (0.34), \%H 1.47 (1.23), \%N $0(0.03)$, K/Mn 0.2325 (0.2325); for K-OMS-2 helix, K/Mn 0.2325 (0.2325). The flexibility of the helices may be due to elastic anisotropy resulting from the fibrous texture of the gel.

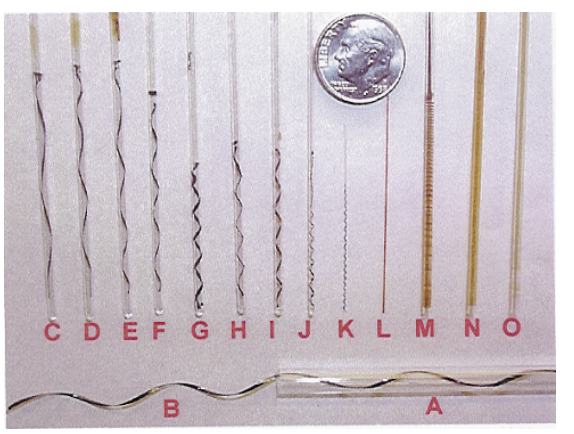

Figure 1 Morphology of self-assembled (TMA) $\mathrm{MnO}_{x}$ structures. Different samples $\mathrm{A}-0$ represent colloids produced by varying manganese concentration, capillary diameter, temperature, and heating period (Table 1). The encapsulated self-assembled products are shown as the final morphology attained after solvent evaporation at $85^{\circ} \mathrm{C}$. Coin diameter is $18 \mathrm{~mm}$.

fusion. The anisotropic (that is, larger by an order of magnitude in the direction parallel to the helix axis compared with the perpendicular direction) DC-4 probe conductivity of $4.2 \times 10^{-1} \mathrm{~W}^{-1} \mathrm{~cm}^{-1}$ at $21{ }^{\circ} \mathrm{C}$ for the K-OMS-2 system is roughly an order of magnitude more conductive than most wellformed single crystals of semiconducting cryptomelane-like materials ${ }^{12}$.

Oscar Giraldo*, Stephanie L. Brock*, Manuel Marquez ${ }^{\star}$, Steven L. Suib ${ }^{\star} \dagger$, Hugh Hillhouse§, Michael Tsapatsis $\S$ Departments of ${ }^{*}$ Chemistry and $\dagger$ Chemical Engineering and $\ddagger$ Institute of Materials Science, University of Connecticut, Storrs, Connecticut 06269-3060, USA

e-mail: suib@uconnvm.uconn.edu

$\$$ Department of Chemical Engineering,

159 Goessmann Laboratory, University of

Massachusetts, Amherst, Massachusetts

01003-3110, USA

\footnotetext{
1. Wu, C. G. \& Bein, T. Science 264, 1757-1759 (1994).

2. Trau, M. et al. Nature 390, 674-676 (1997).

3. den Exter, M. J. et al. in Recent Advances and New Horizons in Zeolite Science and Technology (ed. Chon, H.) Vol. 102, 413-454 (Stud. Surf. Sci. Catal., Elsevier, Amsterdam, 1996).

4. Jones, C. W., Tsuji, K. \& Davis, M. E. Nature 393, 52-54 (1998).

5. Davis, W. B. et al. Nature 396, 60-63 (1998).

6. Rowan, A. E. \& Nolte, R. J. M. Angew. Chem. Int. Ed. 37, 63-68 (1998).

7. Soghomonian, V. et al. Science 259, 1596-1599 (1993)

8. Gier, T. E., Bu, X., Feng, P. \& Stucky, G. D. Nature 395, 154-157 (1998).

9. Raimondi, M. E., Maschmeyer, T., Templer, R. H. \& Seddon, J. M. J. Chem. Soc. Chem. Comm. 19, 1843-1844 (1997).

10. Bruinsma, P. J. et al. Chem. Mater. 9, 2507-2512 (1997).

11. Antal, T., Droz, M., Magnin, J. \& Racz, Z. Phys. Rev. Lett. 83, 2880-2883 (1999).

12. Shen, Y. F. et al. Science 260, 511-515 (1993).
}

\section{Erratum}

Stomach rinsing in rays

D. W. Sims, P. L. R. Andrews, J. Z. Young

Nature 404, 566 (2000)

An editing error caused a misrepresentation of results reported in ref. 8: in the first sentence of the third-to-last paragraph, the intended meaning is that cloacal protrusion has been described in the Carcharhinidae, and not peritoneal-inflation-induced cloacal protrusion as the text implies.

NATURE | VOL 405 | 4 MAY 2000 | www.nature.com 


\section{Stomach rinsing in rays}

- he vomiting reflex is a protective mechanism for the bulk ejection of noxious material, and is common in vertebrates $^{1}$. Here we show that the thornback ray Raja clavata (Rajidae) can 'rinse' its stomach by full gastric eversion, washing small indigestible food particles and sloughed gastric mucosa and mucus out of the upper digestive tract. This may be a widespread mechanism, besides vomiting, for fish to remove noxious material from the stomach.

Skates and rays are ubiquitous and comprise nearly half the 900 known species of Elasmobranchii (sharks, skates and rays). We studied the vomiting responses of $R$. clavata caught in the English Channel and fed on chopped fish and squid in the laboratory. Individual $R$. clavata were given an emetic $^{1}$, veratrine hydrochloride $(10 \mathrm{mg}$ $\mathrm{kg}^{-1}$ i.p. in elasmobranch ringer; $n=4$ ), or ringer $(n=3)$. After injection we placed them in a glass-sided tank and recorded their behaviour on video.

Stomach eversion and swallowing of the everted stomach occurred within $10 \mathrm{~min}$ of drug injection, but not in rays given ringer. Eversion was frequent: in one animal, it occurred nine times in four discrete bursts post-injection (three eversions between 351 and $361 \mathrm{~s}$; one at $404 \mathrm{~s}$; three between 425 and $430 \mathrm{~s}$; two at $463 \mathrm{~s}$ ). Immediately before eversion, the mouth was wide open, the jaws protruded and the buccal and pharyngeal cavities expanded (Fig. 1). The stomach prolapsed and was fully everted $0.5-2.0 \mathrm{~s}$ later, concomitant with a strong contraction of the pharynx. The outline of the hypo- and basi-branchial cartilages under the skin was visible externally, indicating contraction of the coraco-mandibularis, -hyoideus and -branchiales muscles (see frame 7:08:51).

The entrance to the pylorus on the stomach's mucosal surface was visible, indicating that the stomach was fully everted. This was accompanied by lateral shaking of the head, a behaviour also seen in vomiting dogfish ${ }^{1}$. Between 0.2 and $2.0 \mathrm{~s}$ later, when the pharyngeal cavity expanded, the stomach was retracted into the mouth. We assume that it was swallowed in the next $0.1-0.2 \mathrm{~s}$, as it was not visible inside the oral cavity, and maximal jaw protrusion and mouth closure followed rapidly — behaviour consistent with the normal prey-capture responses of rays before swallowing. The material ejected ranged from small pieces of fish to a particulate mucoid suspension.

These observations show that rays evert and swallow their stomachs in response to an agent that induces vomiting in other fish (such as dogfish) ${ }^{1}$ and vertebrates (such as

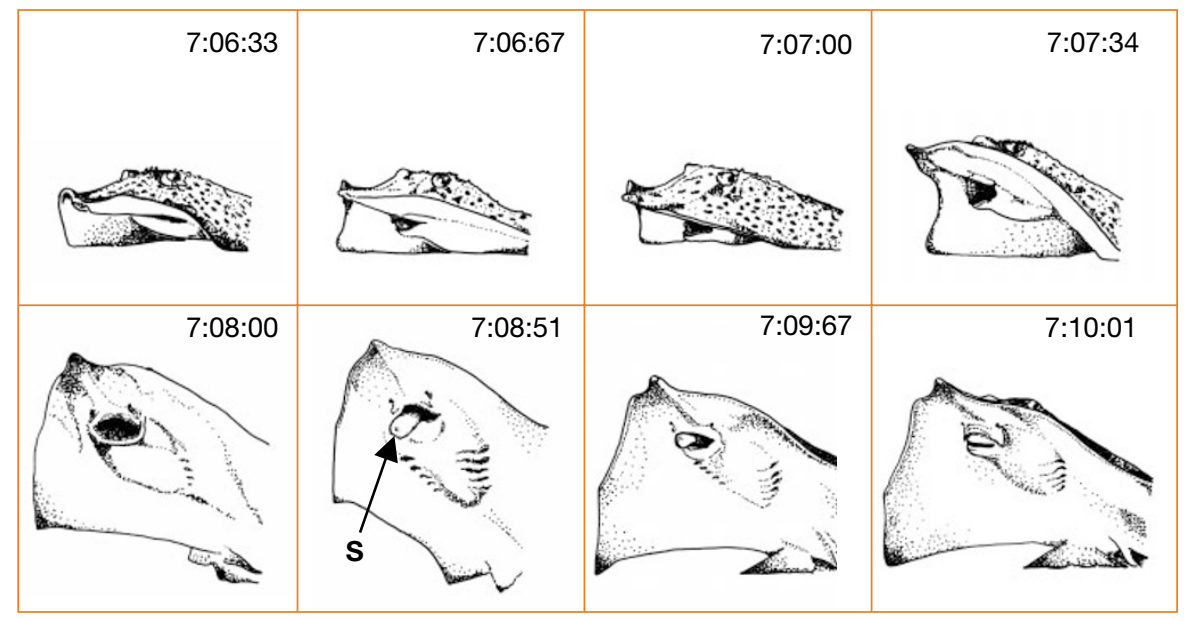

Figure 1 Temporal sequence of stomach eversion and swallowing in Raja clavata. Number in each frame refers to elapsed time (minutes: seconds: hundredths of a second) from injection of veratrine. S, cardiac stomach. Video recordings of behaviour were analysed by taking monochrome digitalized still images, constituting individual frames, from the videotape at selected time intervals using a Pana sonic NVMP1 video printer.

crocodiles and cats $)^{2,3}$. We do not know how the stomach is everted, but it probably involves profound relaxation of the gastric musculature and a rapid increase in intraabdominal pressure. Some amphibians also prolapse the oesophagus and stomach through the mouth during vomiting ${ }^{4,5}$, and intense abdominal muscle contraction has been reported as the mechanism for oral eversion in ten species of frogs and toads ${ }^{6}$.

Post-mortem studies of wild-caught rays ( $n=6$ ) show that oral eversion of the stomach could be induced by gas inflation of the peritoneal cavity using a pressure of about $200 \mathrm{~mm} \mathrm{Hg}$. We also found that chitinous food residues, such as prawn exoskeletons, and larger pieces of fish can also be ejected by this procedure.

In rays, the oral eversion of the stomach is not impeded by mesenteric attachments of the gut to the body wall ${ }^{7}$. The short distance from the mouth to the stomach and the short, wide oesophagus - common to both rays and frogs and toads - presumably act to facilitate eversion.

Cloacal protrusion of the valvular intestine in rays could not be induced by peritoneal inflation, although it can be in members of the shark family Carcharhinidae ${ }^{8}$. There are no descriptions of vomiting in these species, but fishermen have observed line- and net-caught sharks with everted stomachs, possibly due to capture; however, post-eversion stomach swallowing has not been recorded ${ }^{9}$.

Nonetheless, there is anecdotal evidence that stomach eversion and swallowing occurs in three carcharhinid shark species (Carcharhinus cautus, Negaprion brevirostris, Prionace glauca) and a guitarfish (Rhinobatos typus) (C. Grist, J. Ugoretz and W. White, personal communication). A lemon shark, $N$. brevirostris, was seen to evert its stomach naturally, where it hung limply out of one side of the mouth before head-shaking released an oily 'scum' from the surface of the stomach, which was then retracted slowly through the mouth and swallowed. The whole episode lasted 25-30 seconds.

We suggest that sharks and rays can externalize most of their alimentary canal, and that this process serves to remove parasites, indigestible material, toxic food, and sloughed gastric mucosa and mucus. The last of these could also be used to excrete accumulated toxic metabolites - as in chinstrap penguins, which excrete fluoride by vomiting their stomach linings ${ }^{10}$. In frogs and toads, stomach eversion is accompanied by 'gastric grooming' with the right hand to wipe away vomitus ${ }^{6}$. We propose that rays' head-shaking during oral eversion fulfils a similar function, and rinses the stomach of persistent small particles and mucus.

David W. Sims*, Paul L. R. Andrews $\dagger$,

\section{J. Z. Young $\ddagger$}

${ }^{*}$ Department of Zoology, University of Aberdeen,

Tillydrone Avenue, Aberdeen AB24 2TZ, UK

e-mail:d.w.sims@abdn.ac.uk

$\dagger$ Department of Physiology, St George's Hospital Medical School, Cranmer Terrace, London

SW17 ORE, UK

$\ddagger$ Department of Experimental Psychology, University of Oxford, South Parks Road, Oxford OX1 3UD, UK

\$Deceased

1. Andrews, P. L. R., Sims, D. W. \& Young, J. Z. J. Mar. Biol. Assoc. UK 78, 1269-1280 (1998).

2. Andrews, P. L. R. et al. J. Exp. Biol. (in the press).

3. Borison, H. L. \& Fairbanks, V. F. J. Pharmacol. Exp. Therapeut. 105, 317-325 (1952).

4. Naitoh, T. \& Wassersug, R. J. Nature 380, 30-31 (1996).

5. Naitoh, T. et al. Physiol. Zool. 62, 819-843 (1989).

6. Naitoh, T., Imamura, M. \& Wassersug, R. J. Comp. Biochem. Physiol. 100C, 353-359 (1991).

7. Wake, M. H. (ed.) Hyman's Comparative Vertebrate Anatomy (Univ. Chicago Press, Chicago, 1979).

8. Crow, G. L. et al. Copeia 1990, 226-229 (1990).

9. Budker, P. The Life of Sharks (Weidenfeld \& Nicolson, London, 1971).

10. Beintema, A. J. Nature 352, 480-481 (1991). 